\title{
Bakır(II) Komplekslerinin Glutatyon Redüktaz İnhibitor Çalışması
}

\section{Studies of Glutathione Reductase Inhibitors Activity of Copper(II) Complexes}

\author{
Turgay Tunç*
}

Geliş / Received: 13/06/2019

Revize / Revised: 18/07/2019

Kabul / Accepted: 08/09/2019

$\ddot{O}$

Z- (S)-(+)-fenilglisinol, (1S, 2R) -2-amino-1,2-difeniletanol'in ve (R)-(+)-2-amino-1,1,3-trifenilpropanol bazlt kiral Schiff bazlarının bakır (II) kompleksi sentezlendi. Bu bileşiklerin glutatyon redüktaz enzimi üzerindeki etkileri incelendi. En iyi inhibitör etkisinin kompleks 3'e ait olduğu belirlenmiştir.

Anahtar Kelimeler- Schiff Baz, Bakır (II) Kompleksleri, Glutatyon Redüktaz.

bstract- (S)-(+) - phenylglycinol, (1S, 2R)-2-amino-1, 2-diphenylethanol and (R)-(+)-2-amino-1, 1, 3triphenylpropanol based chiral copper (II) complex of Schiff bases were synthesized. The effects of these compounds on glutathione reductase enzyme were investigated. The best inhibitory effect was found to belong to complex 3 .

Keywords- Schiff Bases, Copper (II) Complexes, Glutathione Reductase.

*Sorumlu yazar iletişim: ttunc@ahievran.edu.tr (https://orcid.org/0000-0002-2431-8027)

Kimya ve Proses Mühendisliği, Kırşehir Ahi Evran Üniversitesi, Bağbaşı Kampüsü, Merkez /Kırşehir 


\section{GİRIŞ̧}

Canlılar reaktif oksijen türlerinin etkilerini nötralize eden antioksidan savunma sistemine sahiptir [1-4]. Reaktif oksijen türleri ile antioksidanlar arasındaki dengenin bozulması sonucu "oksidatif stress" meydana gelir, hücre içindeki proteinler, lipitler, yağlar ve nükleik asitlerde hasara neden olurlar [5,6]. Oksidatif stresin günümüzde kanser, kalp yetmezliği gibi birçok hastalığın oluşumunda rol oynadığı bilinmektedir $[7,8]$.

Glutatyon (GSH) DNA ve protein sentezinde, amino asitlerin taşıımında [9, 10] rol aldığı gibi disülfürlerine (GSSG) yükseltgenerek hücreleri oksidatif strese karşıda korur [11-14]. Glutatyon Redüktaz (GR), GSSG' nin GSH' a indirgenmesini katalizler ve indirgen olarak NADPH kullanır $[15,16]$. GR inhibitörleri, oksidatif stres ve bununla ilgili hastalıkların araştırılmasında kullanılmaktadırlar, GR inhibitörleri oksidatif stresi artırarak tümörlerin çoğalmasını engeller. GSSG birikmesi DNA sentezini inhibe edip, hücre fonksiyonlarını bozduğu için GR inhibitorleri kanser ilacı olarak da kullanılırlar [17, 18].

Schiff bazları ve bunların metal kompleksleri sentez kimyası ve farmasetik kimyanın araştırdığı önemli konulardan biridir $[19,20]$. Schiff-bazlarının bakır kompleksleri antitiümor, antimikrobiyal, antivirüs v.s. gibi çeşitli biyolojik aktiviteye sahip olmalarının yanı sıra $\mathrm{Cu}$ metali hücrede $\mathrm{Cu}(\mathrm{II})$ katyonuna yükseltgenmekte ve GSH ile kompleks oluşturarak hücre içindeki GSH/GSSG oranını düşürmekte ve hücreye zarar vermektedir [21].

\section{MATERYAL VE METOT}

\section{A. Reaktifler ve kimyasallar}

Ekmek mayasından elde edilmiş GR (E.C 1.6.4.2; $160 \mathrm{U}$ per mg-1 of protein) ve diğer kimyasallar (GSSG, GSH, NADPH, $\mathrm{NaH}_{2} \mathrm{PO}_{4}, \mathrm{Na}_{2} \mathrm{HPO}_{4}$, and DMSO) Sigma-Aldrich' den satın alınmıştır.

\section{B. Schiff base ligandlarinin ve Komplekslerin sentezi}

Çalışmada kullanılan ligantlar ve kompleksler literatüre göre aşağıdaki genel sentez yöntemine göre sentezlenmiştir [22, 23].

1<smiles>OC[C@H](N=Cc1ccccc1O)c1ccccc1</smiles>

2<smiles>Oc1ccccc1/C=N/[C@H](c1ccccc1)[C@H](O)c1ccccc1</smiles>

3<smiles>Oc1ccccc1/C=N/[C@H](Cc1ccccc1)C(O)(c1ccccc1)c1ccccc1</smiles><smiles>CC(=O)O[Ge]12OC[C@@H](c3ccccc3)N1Cc1ccccc1O2</smiles>

Şekil 1. Sentezlenen bileşiklerin yapısı. 


\section{Schiff Bazlarının Genel Sentezi}

Etanol $(25 \mathrm{ml})$ içerisindeki $o$-hidroksibenzaldehit $(100 \mathrm{~mL}, 15 \mathrm{mmol})$ çözeltisine, etanol $(25 \mathrm{ml})$ içerisindeki S)-(+)-fenilglisinol, (1S, 2R) -2-amino-1,2-difeniletanol'in ve (R)-(+)-2-amino-1,1,3-trifenilpropanol (18 mmol) ilave edildi. Karışım 16 saat geri soğutucu altında kaynama sıcaklığında karıştırıldı. Karışım oda sıcaklığına soğutularak çözücü vakum altında uzaklaştırıldı. Ham ürün etil asetatta kristallendirildi [22].

\section{Bakır Komplekslerinin Genel Sentezi}

Kiral Schiff bazının metanol çözeltisine (10 mL, $0.064 \mathrm{mmol})$ damla damla bakır (II) asetat (0.064 mmol, $11.7 \mathrm{mg}$ ) ilave edildi. Karışım daha sonra iki saat boyunca $60^{\circ} \mathrm{C}^{\prime}$ de geri soğutucu altında karıştırıldı. Reaksiyon tamamlandıktan sonra, karışım soğumaya bırakıldı ve 2 gün oda sıcaklığında bekletildi. Yeşil katı madde süzüldü, iki kez soğuk metanol ile yıkandı ve vakum altında kurutuldu [23].

\section{E. Glutatyon Redüktaz Aktivitesinin Belirlenmesi}

Glutatyon redüktaz enzim aktivitesini belirlemek için oda sıcaklığında UV-Vis. küvete fosfat tampon (pH:7.2), NADPH $\left(1.10^{-4} \mathrm{M}\right)$ ve GSSG $\left(2.10^{-4} \mathrm{M}\right)$ eklendikten sonra karışım dikkatlice karıştırıldı ve ön inkübasyon için 3 dakika bekletildi. Reaksiyon glutatyon redüktaz (1 U) eklenerek başlatıldı ve her 30 saniyede bir olmak üzere NADPH’ in oksidasyonu 120 saniye boyunca takip edilerek absorbans ölçümleri alındı [24]. Aynı işlem farklı derişimlerdeki kompleks çözeltileri eklenerek en az 5 ölçüm alınarak tekrarlandı ve elde edilen verilerin ortalama değerleri kullanıldı. Bu verilerden $I C_{50}$ değeri grafiksel olarak belirlendi.

Enzim ünitesi hesaplanırken aşağıdaki formül kullanıldı.

$E \ddot{\mathrm{U}} / m l=\Delta O D / 6.22 \times V T / V E$

EÜ/mL: 1 mL' deki enzim ünitesi.

$\Delta \mathrm{OD}$ : Bir dakikadaki absorbans değişimi.

6,22: 1 mM NADPH' in oluşturduğu absorbans değeri.

VT: Toplam küvet hacmi.

VE: Enzim hacmi.

\section{F. IC $C_{50}$ De ğerlerinin Belirlenmesi}

Farklı inhibitör derişimin de aktivite ölçümü yapılarak komplekslerin \%aktivite-kompleks derişimi grafikleri çizildi, eğri denklemlerinden komplekslerin $\mathrm{IC}_{50}$ değerleri hesaplandi.

$$
\begin{aligned}
& \text { \%inhibisyon }=\frac{\text { inhibitörsüz enzim ünitesinin değeri-inhibitörlü enzim ünitesi değeri }}{\text { inhibitörsüz enzim ünitesi değeri }} \times 100 \\
& \% \text { aktivite }=100-\% \text { inhibisyon. }
\end{aligned}
$$

Tablo 1. Komplekslerin $\mathrm{IC}_{50}$ verileri.

\begin{tabular}{cc}
\hline Kompleks & $\mathrm{IC}_{50}(\mu \mathrm{M})$ \\
\hline $1 \mathrm{a}$ & 158.97 \\
$2 \mathrm{a}$ & 146.93 \\
3a & 133.81 \\
\hline
\end{tabular}




\section{SONUÇ VE TARTIŞMALAR}

Gale W. Rafter tarafından gerçekleştirilen bakır(II) bileşiklerinin literatürdeki $\mathrm{IC}_{50}$ değerlerine bakıldığında 60-2000 $\mu \mathrm{M}$ arasında değişen sonuçların bulunduğu görülmektedir [25]. Sentezlenmiş olan bileşiklerin $I C_{50}$ değerleri karşılaştırıldığında en iyi sonucun 3 a bileşiğinin verdiği görülmüştür. Bu durumun $3 \mathrm{a}$ bileşiğindeki aromatik grupların sayısının çok olması sebebiyle GR enzimi ile daha fazla moleküller arası etkileşim yaptığından kaynaklandığı düşünülebilir. Elde edilen sonuçlar literatüre katkı sağlayacağı gibi GR enzimine etki eden yeni etken maddelerin geliştirilmesinde yardımcı olacaktır.
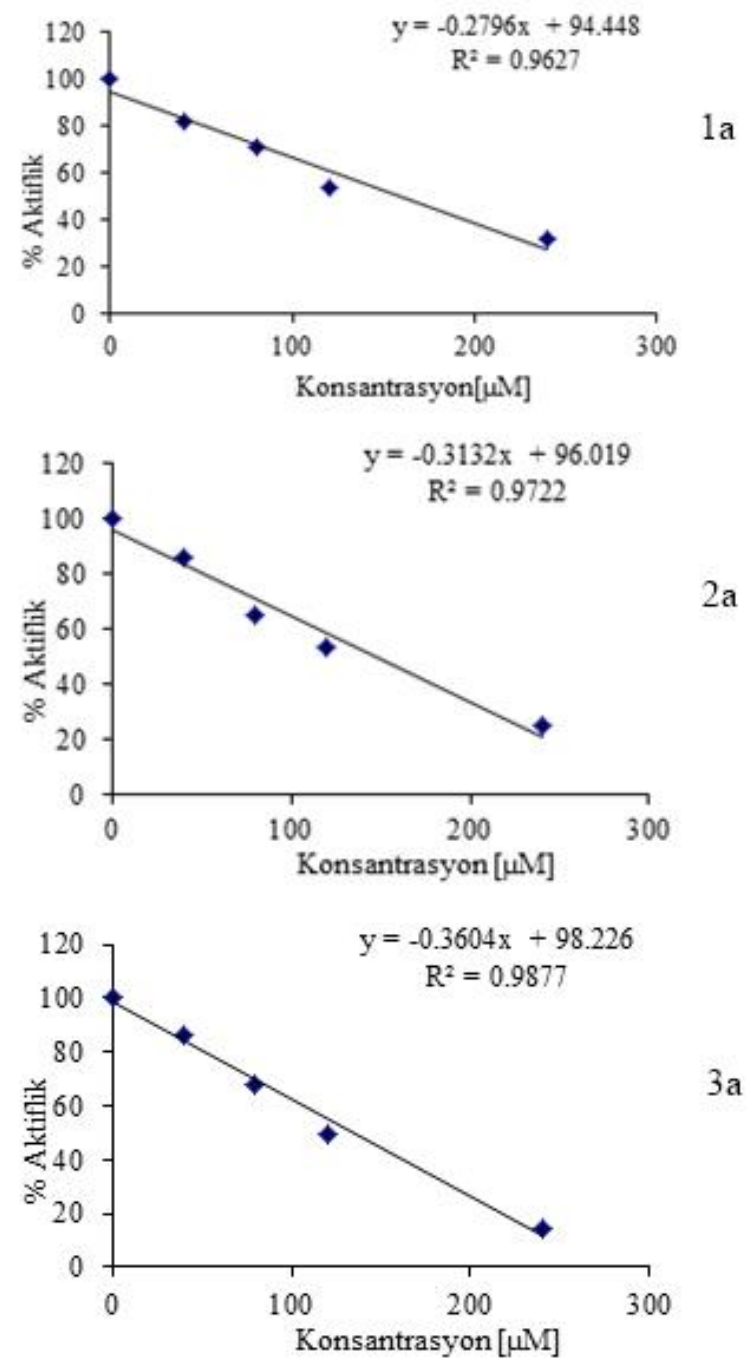

Şekil 2. Komplekslerin \% Aktivite-Kompleks derişimi grafiği.

\section{KAYNAKLAR}

[1] Blanck, S., Maksimoska, J., Baumeister, J., Harms, K., Marmorstein, R., Meggers, E. (2012). “About the Art of Filling Protein Pockets Efficiently with Octahedral Metal Complexes”, Angew. Chem. Int. Ed. 51, 5244-5246.

[2] Barber, D., and Harris, S. (1994). "Oxygen free radicals and antioxidants: a review”. Journal of The American Pharmacists, NS34, 26-35.

[3] Yruela, I. (2005). “Copper in plants”, Brazilian Journal of Plant Physiology, 17, 145-156. 
[4] Chena, H., Chena, J., Guona, Y., Wena, Y., Liub, J., Liub, W. (2012). "Evaluation of the role of the glutathione redox cycle in $\mathrm{Cu}(\mathrm{II})$ toxicity to green algae by a chiral perturbation approach", Aquatic Toxicology, 120-121, 19-26.

[5] Flikweet, J.P., Hoorn, R.K.J., Staal, G.E.J. (1974). “The effect of copper on human erythrocyte glutathione reductase", Journal of Biochemistry, 649-653, 5.

[6] Rafter, G. W. (1982). "Copper inhibition of glutathione reductase and its reversal with gold thiolates, thiol, and disulfide compounds", Biochemical Medicine, 27, 381-391.

[7] Vigouroux, S., Briand, M., and Briand, Y. (2004). "Linkage between the proteasome pathway and neurodegenerative diseases and aging”, Molecular Neurobiology, 30, 201-221.

[8] Willcox, J. K., Ash, S. L. and Catignani, G. L. (2004). “Antioxidants and prevention of chronic disease”, Critical Reviews in Food Science Nutrition, 44, 275-295.

[9] Meister, A., and Anderson, M. E. (1983). “Glutathione, Annual Reviev of.Biochemistry”, 52, 711-760.

[10] Dolphin, D., Avramovic, O., and Poulson, R. (1989). “Coenzymes and Cofactors, III”, A, John Wiley \& Sons, New York.

[11] Pullela, P., Chiku, T., Carvan, M., and Sem, D. S. (2006). "Fluorescence-based detection of thiols in vitro and in vivo using dithiol probes", Analytical Biochemistry, 352, 265-273.

[12] Patsoukis, N. and Georgiou, C. (2004). "Determination of the thiol redox state of organisms: new oxidative stress indicators", Analytical and Bioanalytical Chemistry, 378, 1783-1792.

[13] Asmis, R., Wang, Y., Xu, L., Kisgati, M., Begley, J. G., and Mieyal, J. J. (2005). “A novel thiol oxidationbased mechanism for adriamycin-induced cell injury in human macrophages", The Journal of The Federation of American Societies for Experimental Biology, 19, 1866-1868.

[14] Patsoukis, N. and Georgiou, C. (2005). "Fluorometric determination of thiol redox state", Analytical and Bioanalytical Chemistry, 383, 923-929.

[15] Henderson, B., Fairlamb, A. H., and Cerami, A. (1987). "Trypanothione dependent peroxide metabolism in Crithidia fasciculata and Trypanosoma brucei”, Molecular Biochemistry Parasitology, 24, 39-45.

[16] Fairlamb, A. H., Blackburn, P., Ulrich, P., Chait, B. T., and Cerami, A. (1985). "Trypanothione a novel bis(glutathionyl)spermidine cofactor for glutathione reductase in trypanosomatids", Science, 222, 14851487.

[17] Dolphin, D., Avramovic, O., and Poulson, R., (1989). "Glutathione reductase. In Glutathione: Chemical, Biochemical, and Medical Aspects. Part A”., Wiley-Interscience: New York, 553-596.

[18] Karplus, P. A., Krauth, S. R. L., Schirmer, R. H., and Schulz, G. E. (1988). "Inhibition of human glutathione reductase by the nitrosourea drugs 1,3-bis(2-chloroethyl)-1- nitrosourea and 1-(2-chloroethyl)-3-(2hydroxyethyl)-1-nitrosourea. A crystallographic analysis", European Journal Biochemistry, 171 (52), 193 198.

[19] Kumar, S., Dhar, D. N., Saxena, P. N. (2009). "Applications of metal complexes of Schiff bases-A review", Journal of Scientific and Industrial Research, 68, 3, 181-187.

[20] Sadimenko, A. P. Edited by: Katritzky, A. R. (2012). "Organometallic Complexes of Pyridyl Schiff Bases”, Advances in Heterocyclic Chemistry, Book Series: Advances in Heterocyclic Chemistry, 107, 133-218.

[21] Katwal, R., Kaur, H., Kapur, B. K. (2013). "Applications of copper - Schiff's base complexes: a review", Scientific Reviews \& Chemical Communications, 3, 1, 1-15.

[22] Çolak, M., Aral, T., Hoşgören H., Demirel, N. (2007). Synthesis of Novel Chiral Schiff-Base Ligands and Their Application in Asymmetric Nitro Aldol (Henry) Reaction, Tetrahedron Asymmetry., 18, 1129. 
[23] Tunç, T., Demirel, N., Emir, M., Günel, A., Çolak, M., Karacan, N. (2018). DNA binding and cleavage activity of three new copper (II) complexes of chiral N-salicyl- $\beta$-amino alcohol Schiff bases, J. Mex. Chem. Soc., 62(3), 51-66.

[24] Guan, X., Hoffman, B. N., McFarland, D. C., Gilkerson, K. K., Dwivedi, C., Erickson, A. K., Bebensee, S., and Pellegrini, J. (2002). Glutathione and mercapturic acid conjugates of sulofenur and their activity against a human colon cancer cell line, Drug Metabolism and Disposition, 30, 331-335.

[25] Rafter, W. G. (1981). Copper inhibition of glutathione reductase and its reversal with gold thiolates, thiol, and disulfide compounds, Biochemical Medicine, 27, 381-391. 